\title{
Depolarization of Nonmyelinated Fibers of the Rat Vagus Nerve Produced by Activation of Protein Kinase C
}

\author{
H. P. Rang and J. M. Ritchie ${ }^{\top}$ \\ Sandoz Institute for Medical Research, London WC1E 6BN, England, and 'Department of Pharmacology, Yale University \\ School of Medicine, New Haven, Connecticut 06510
}

The effect of activation of protein kinase $\mathbf{C}$ by phorbol esters has been studied on the nonmyelinated $(C)$ fibers of the rat vagus nerve. Grease-gap recording at room temperature was used to monitor changes in the resting and action potentials. Effects of phorbol esters on the rate of efflux of ${ }^{86} \mathrm{Rb}$ and ${ }^{14} \mathrm{C}$-guanidinium were also measured.

The active isomer $\beta$-phorbol 12,13-dibutyrate (PDBu), applied for $10 \mathrm{~min}$ at concentrations of $10 \mathrm{nM}$ to $3 \mu \mathrm{M}$, caused a slowly developing depolarization, which persisted after the drug was washed out. The action potential was concomitantly reduced. These effects did not occur with the inactive isomer $\alpha$-phorbol 12,13-didecanoate.

The PDBu-induced depolarization was reduced by about $75 \%$ if $\mathrm{Na}^{+}$was replaced by the impermeant cation $\mathrm{N}$-methyl(+)-glucamine (NMG); the residual effect was almost abolished if the nerves were presoaked in a solution containing gluconate in place of $\mathrm{Cl}^{-}$. It was concluded that increases in conductance mainly to $\mathrm{Na}^{+}$and $\mathrm{Cl}^{-}$were responsible for the depolarization. The response was unaffected by tetrodotoxin or calcium-channel blockers.

Omission of $\mathrm{Ca}^{2+}$, surprisingly, enhanced the PDBu-induced depolarization 3-5-fold; furthermore, addition of $2 \mathrm{~mm}$ $\mathrm{Ca}^{2+}$ following a PDBu-induced depolarization recorded in $\mathrm{Ca}^{2+}$-free solution caused a pronounced repolarization. This effect of $\mathrm{Ca}^{2+}$ occurred also with $\mathrm{Sr}^{2+}$ and $\mathrm{Ba}^{2+}$, but not with other divalent cations or with $\mathrm{La}^{3+}$. Divalent cations known to block $\mathrm{Ca}$ channels inhibited the repolarizing action of $\mathrm{Ca}^{2+}$. These results suggested that $\mathrm{Ca}^{2+}$ acts intracellularly, either to block Na channels opened by PDBu or to activate protein phosphatases.

The PDBu-induced response in $\mathrm{Ca}^{2+}$-free solution was increased 2-fold by a reduction in $\mathrm{pH}$ from 7.4 to 6.5 . Under normal conditions the nerve was reversibly depolarized by this pH change; after PDBu this pH sensitivity was enhanced, and depolarization occurred at a less acidic $\mathbf{p H}$.

PDBu caused a 3-4-fold increase in the rate of efflux of ${ }^{86} \mathrm{Rb}$ (a marker for $\mathrm{K}^{+}$ions) and of ${ }^{14} \mathrm{C}$-guanidinium (a marker for $\mathrm{Na}^{+}$ions) from preloaded nerves. These effects, in con-

Received Aug. 20, 1987; revised Nov. 23, 1987; accepted Nov. 27, 1987

This work was supported by grants to J.M.R. from the USPHS (NS12327, NS08304), from the US National Multiple Sclerosis Society (RG 1162), and by a travel grant to J.M.R. from the Wellcome Trust. We are grateful to Elizabeth Reed and Helen Griffiths for able technical assistance, and to Dr. G. M. Burgess for advice and discussion.

Correspondence should be addressed to Dr. H. P. Rang, Sandoz Institute for Medical Research, 5 Gower Place, London WC1E 6BN, England.

Copyright (C) 1988 Society for Neuroscience $0270-6474 / 88 / 072606-12 \$ 02.00 / 0$ trast to the depolarization, were transient. The effects were unaltered or only slightly reduced in the presence of 4-aminopyridine and tetrodotoxin respectively, and it was concluded that voltage-sensitive $\mathrm{Na}^{+}$and $\mathrm{K}^{+}$channels were not responsible for the increased efflux rates.

It is concluded that activation of protein kinase $C$ causes C-fiber depolarization mainly by opening $\mathrm{Na}^{+}$and $\mathrm{Cl}^{-}$channels. The $\mathrm{Na}^{+}$channels are unaffected by tetrodotoxin, and are unusual in their sensitivity to $\mathrm{pH}$ and divalent cations. $\mathrm{A}$ role for kinase $\mathrm{C}$ in the chemical excitation of nociceptive sensory neurons is a possibility.

Although it has been known for some time that the second messenger cyclic AMP has a large number of effects on neurons and other types of cell, it has only recently become clear that a major factor in the regulation of neuronal activity involves another second messenger, diacylglycerol, which activates protein kinase C. This enzyme, once activated, is known to phosphorylate, and hence regulate, the function of a variety of channels (calcium, potassium, and chloride); it similarly controls the amount of transmitter released by nerve cells (Shapira et al., 1987; see reviews by Miller, 1986; Kaczmarek, 1987). For example, activation of protein kinase $C$ increases the calcium current in some cells, such as Aplysia bag cell neurons (DeRiemer et al., 1985b), but decreases it in others, such as dorsal root ganglion neurons (Rane and Dunlap, 1986) and secretory cells (Di Virgilio et al., 1986). Furthermore, in some parts of the central nervous system, activation of kinase $C$ underlies longterm potentiation of synaptic responses (Akers et al., 1986; Malenka et al., 1986).

Some of the experimental work establishing the role of protein kinase $\mathrm{C}$ in the regulation of ion channels and neuronal transmitter release has involved the direct injection of the enzyme into neurons (DeRiemer et al., 1985a, b). However, most experimental work has involved exposing intact nerve cells to activators of protein kinase $\mathrm{C}$, in particular some of the tumorpromoting phorbol esters (see Nishizuka, 1984, 1986). These esters, being lipophilic, readily enter membranes of intact cells, and, as they are not rapidly metabolized (see Nishizuka, 1986), they produce a long-lasting activation of protein kinase $\mathrm{C}$ and, consequently, long-lasting effects on neuronal excitability. Recent work (Lindsay and Rang, 1988) has shown that activation of protein kinase $\mathrm{C}$ by phorbol esters causes a depolarization and increased membrane conductance in rat sensory neurons grown in culture. These findings prompted the present study of the electrophysiological effects of kinase $C$ activation on the rat vagus nerve in vitro. This nerve consists mainly of nonmyelin- 
ated (C-) fibers, most of which are sensory. These experiments, of which a preliminary report has already been made (Rang and Ritchie, 1987), have shown that, in addition to the previously described effects on potassium and calcium conductances, activation of protein kinase $\mathrm{C}$ leads to an increase in sodium conductance of $\mathrm{C}$-fibers, with a consequent depolarization. Chloride conductance also seems to be increased, although the evidence for this is less conclusive.

\section{Materials and Methods}

The vagus nerves of adult Sprague-Dawley rats, killed by exposure to $100 \% \mathrm{CO}_{2}$, were rapidly removed, desheathed, and then mounted in the recording chamber.

Electrical recording. The nerve was mounted in a grease-gap recording chamber. This consisted of a narrow channel $(0.3 \mathrm{~mm}$ diameter, $10 \mathrm{~mm}$ length) through a plastic block, through which the nerve was pulled. The channel was filled with petroleum jelly (Vaseline) injected through a side-arm when the nerve was in place. One end of the nerve emerged into a wider channel, and was continuously superfused with Locke's solution at room temperature (about $20^{\circ} \mathrm{C}$ ), flowing at $1-2 \mathrm{ml} / \mathrm{min}$. This channel was also equipped with platinum wire electrodes for stimulation of the nerve at a point $10 \mathrm{~mm}$ from the recording site, which was at the junction between the grease-filled channel and the superfused region of the nerve. The other end of the nerve emerged into a small chamber containing $150 \mathrm{~mm} \mathrm{KCl}$ solution. Cotton wicks were used to make contact with the superfusing solution and the $\mathrm{KCl}$ chamber; these wicks ran via salt-agar bridges to $\mathrm{Ag} / \mathrm{AgCl}_{2}$ electrodes, which were connected to the input of a high-impedance preamplifier (WPI; type M-707A).

The action potential elicited by supramaximal stimuli $(0.5 \mathrm{msec}$ duration) was recorded on a digital storage oscilloscope, and the resting potential recorded on a chart recorder. In addition, both the action and resting potentials were recorded on a tape recorder (Racal 4D). The small size of mammalian C-fibers necessitates the use of extracellular, rather than intracellular, recording methods. The use of Vaseline rather than a sucrose gap had the advantage of long-term stability over a period of $0.5-2 \mathrm{hr}$, but the signals were smaller because of the greater shunting. For example, the action potential was usually 1-2 $\mathrm{mV}$ in amplitude, compared with about $10 \mathrm{mV}$ obtained in similar experiments with a sucrose gap (see, for example, Rang and Ritchie, 1968).

Solutions. The composition of the normal Locke's solution was (mM) $\mathrm{NaCl}, 154 ; \mathrm{KCl}, 5.6 ; \mathrm{CaCl}_{2}, 2.0 ; \mathrm{HEPES}$ buffer (usually as the sodium salt, $\mathrm{pH} 7.4), 10 ; \mathrm{D}$-glucose, 5.0. Modifications of this normal solution were made as indicated in the text; in sodium-free solution, sodium was replaced by $N$-methyl-(+)-glucamine (NMG), and in chloride-free solution, chloride was replaced by gluconate. The nominally calcium-free solution used in many experiments contained $6 \mu \mathrm{M} \mathrm{Ca}^{2+}$ (measured by atomic absorption spectroscopy).

The hathing medium could be quickly changed by means of a tap, with little or no artifact, the new solution reaching the recording site with a delay of about $15 \mathrm{sec}$ (measured by the delay in response on switching to a high-potassium solution).

The phorbol ester used in most experiments was $\beta$-phorbol 12,13dibutyrate (PDBu); $\beta$-phorbol 12-myristate, 13 -acetate (TPA) and the inactive $\alpha$-analog $4 \alpha$-phorbol 12,13-didecanoate ( $\alpha$-PDD) were also used occasionally. The esters were kept as frozen $\left(-10^{\circ} \mathrm{C}\right)$ stock solutions $(10$ $\mathrm{mm}$ ) in dimethylsulfoxide. Dilutions in Locke's solution were made shortly before use and kept in darkness or dim light.

All drugs were obtained from Sigma.

Ion flux measurements. In some experiments, measurements were made of the effect of phorbol esters on the efflux of ${ }^{86} \mathrm{Rb}$ (used as a marker for potassium ions) and of ${ }^{14} \mathrm{C}$-guanidinium (used as a marker for sodium ions). In these experiments, desheathed vagus nerves were exposed to the isotope in normal Locke's solution $(1-10 \mu \mathrm{Ci} / \mathrm{ml})$ for at least $2 \mathrm{hr}$, which was sufficient to label substantially the internal compartment; in many experiments, overnight soaking (up to $14 \mathrm{hr}$ ) was used, with no detectable effect on the results. Each nerve was then washed in radioisotope-free solution for about $1 \mathrm{hr}$ and then mounted in a 1-Inm-diameter tube altached to the outlet of a fraction collector. The preparation was then superfused at room temperature by means of a peristaltic pump running at $1 \mathrm{ml} / \mathrm{min}$, and 1 or 2 min samples were collected. At the end of the experiment the residual radioactivity was extracted by placing the nerve in $1 \mathrm{M} \mathrm{NaOH}(0.4 \mathrm{ml})$ for a few minutes,
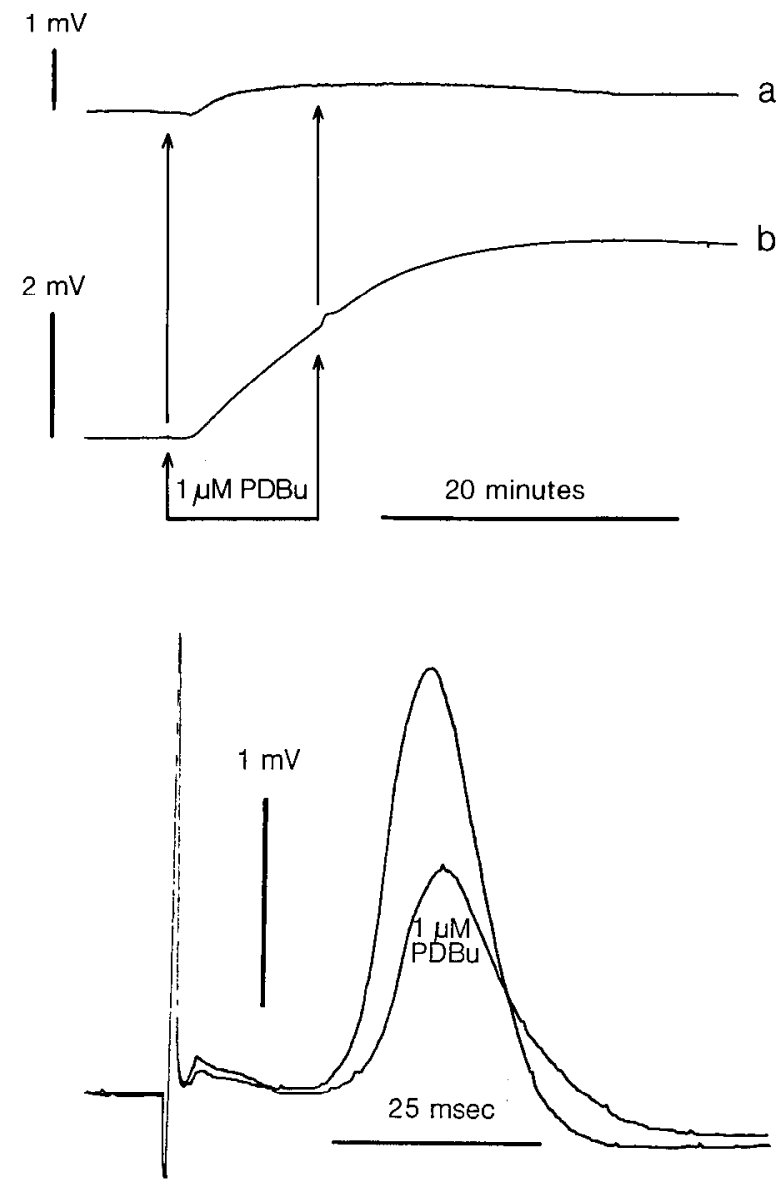

Figure 1. Top, The effect of a $10 \mathrm{~min}$ exposure to $1 \mu \mathrm{M} \beta$-phorbol 12,13-dibutyrate (PDBu) on the resting potential of the nonmyelinated fibers of the desheathed rat vagus nerve $(a)$ in normal Locke's solution ( $2 \mathrm{~mm} \mathrm{Ca}, \mathrm{pH} 7.4)$ and $(b)$ in a calcium-free Locke's solution ( $\mathrm{pH} 7.4)$. Bottom, The compound action potential of rat vagal $\mathrm{C}$-fibers before and after a $10 \mathrm{~min}$ exposure to $1 \mu \mathrm{M} \mathrm{PDBu}$ at $\mathrm{pH} 7.4 .\left[\mathrm{Ca}^{2+}\right]=2 \mathrm{~mm}$.

and the efflux was calculated as a rate constant (i.e., the fractional loss of isotope per minute).

Wherever possible, average values \pm SEM are given

\section{Results}

Figure $1 a$ shows the effect of 10 min exposure to $1 \mu \mathrm{MPDBu}$ on the resting potential of the vagus nerve. After a delay of about $90 \mathrm{sec}$ (which was considerably longer than the solution switchover time of about $15 \mathrm{sec}$ ), a slow depolarization occurred. The depolarization, whose slow onset must have resulted, at least in part, from the rate of diffusion into the nerve bundle, usually continued to develop for some minutes after the preparation was returned to normal Locke's solution. Furthermore, once the depolarization had fully developed, it persisted for the next 20-30 min with little evidence of recovery. This depolarization was accompanied by a slowing of conduction of the compound action potential and a fall in its amplitude (Fig. 1). Subsequent exposure to PDBu produced either no response or, if the preparation was left to recover for several hours, a much reduced depolarization.

These effects of PDBu on the resting and action potentials, though small, were consistently obtained. In normal Locke's solution, the average depolarization at the end of a $10 \mathrm{~min}$ exposure to $1 \mu \mathrm{M}$ PDBu was $0.38 \pm 0.07 \mathrm{mV}(n=10)$, and the 
Figure 2. Effect of a 5 min exposure to $10 \mu \mathrm{M} \alpha-\mathrm{PDD}$, a $10 \mathrm{~min}$ exposure to $1 \mu \mathrm{M} \mathrm{PDBu}$, and a 10 min exposure to TPA on the resting potential of rat vagal C-fibers at pH 6.5 in calcium-free solution.

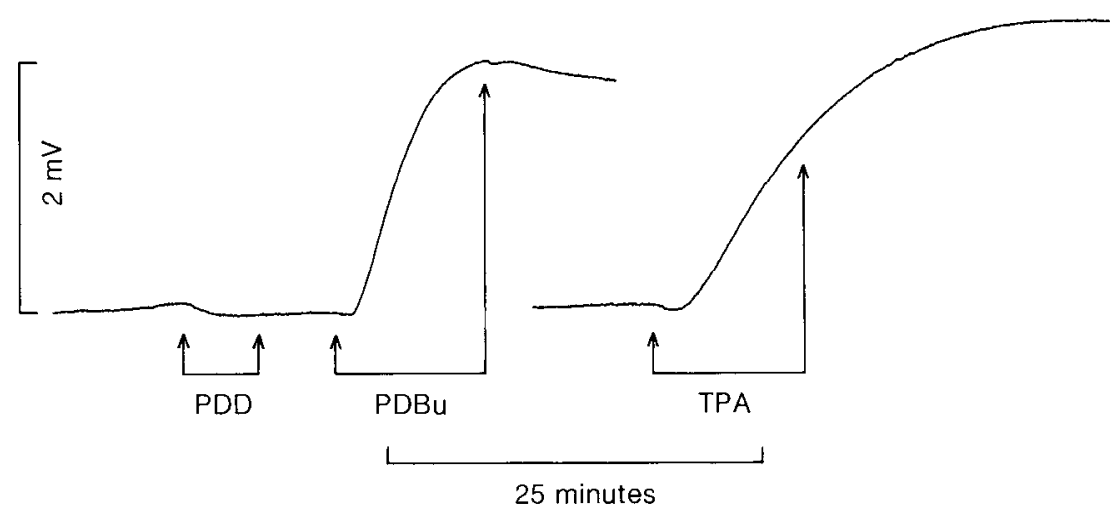

corresponding fall in the amplitude of the $\mathrm{C}$-fiber action potential (control value, $1.85 \pm 0.14 \mathrm{mV} ; n=16$ ) was $20.4 \pm 2.7 \%$. The compound action potential of the myelinated B-fibers, which was often too small to measure, was also reduced (see Fig. 1) by $24.1 \pm 3.9 \%$.

One possible cause of the PDBu-induced depolarization is that there is a rise in calcium permeability of the C-fiber membrane. This possibility is suggested by the findings of Kaczmarek and his colleagues (DeRiemer et al., 1985b; Kaczmarek, 1987; Strong et al., 1987), who found that treatment of isolated bag cell neurons of Aplysia with active phorbol esters increased the amplitude of the voltage-dependent inward calcium current. If that were the case, removal of the extracellular calcium should lead to an abolition or diminution in the response. However, as Figure $1 b$ and Table 1 show, omission of calcium from the bathing solution led to a marked enhancement of the depolarization and of the decrease in amplitude of the compound action potential. On average, at the end of a $10 \mathrm{~min}$ exposure to $1 \mu \mathrm{M}$ $\mathrm{PDBu}$, the depolarization in the calcium-free solution was 0.95 $\pm 0.10 \mathrm{mV}$, and the corresponding fall in the $\mathrm{C}$-fiber action potential $35.0 \pm 2.6 \%(n=18)$; the B-fiber action potential was also reduced, by $32.1 \pm 4.1 \%(n=12)$.

Biochemical experiments have shown that some phorbol esters, such as PDBu and TPA, activate protein kinase C, whereas others, for example, the $\alpha$-phorbol ester PDD, are quite ineffective. As Figure 2 shows, $10 \mu \mathrm{M}$ PDD did not cause depolarization, whereas PDBu and TPA were effective at $1 \mu \mathrm{M}$.

\section{Concentration dependence of PDBu effect}

Most of the experiments were carried out with $1 \mu \mathrm{M} \mathrm{PDBu}$, a concentration reported to produce near-maximal effects (Grega et al., 1987). Figure $3 A$ shows how the depolarization at the end of a 10 min exposure to PDBu varied with concentration. The threshold was about $10 \mathrm{nM}$, and $1 \mu \mathrm{M}$ appeared to be maximal. The true equilibrium relationship would probably be much steeper than that shown in Figure $3 A$, for, at lower concentrations, the response continued to develop substantially after the $\mathrm{PDBu}$ was washed out, whereas at higher concentrations it was virtually complete within the 10 min exposure period.

The true changes in membrane potential produced by the PDBu are necessarily much larger than those recorded extracellularly. Both the resting and action potentials are reduced by the same shunting factor of extracellular recording. However, the compound action potential is reduced further by temporal dispersion, the magnitude of which depends on the conduction distance. The dispersion factor for the $10 \mathrm{~mm}$ conduction distance used in these experiments can be estimated from earlier data (Ritchie and Straub, 1956; Armett and Ritchie, 1960) as reducing the action potential amplitude by about $40 \%$ compared with its amplitude at zero distance. Since the mean amplitude recorded at $10 \mathrm{~mm}$ conduction distance was $1.85 \mathrm{mV}$, the zeroconduction amplitude would have been about $3.1 \mathrm{mV}$. Assuming the membrane action potential to be about $60 \mathrm{mV}$ (see Keynes and Ritchie, 1965), we calculate a shunting factor of

Table 1. Effect on the resting and $\mathrm{C}$ action potentials of a 10 min exposure to $1 \mu \mathrm{M} \mathrm{PDBu}$ in various test solutions in the presence and absence of extracellular calcium ( $2 \mathrm{mM}$ )

\begin{tabular}{|c|c|c|c|c|c|}
\hline \multirow{2}{*}{\multicolumn{2}{|c|}{ Test solution }} & \multicolumn{2}{|l|}{$2 \mathrm{~mm} \mathrm{Ca}$} & \multicolumn{2}{|l|}{$0 \mathrm{mM} \mathrm{Ca}$} \\
\hline & & \multirow{2}{*}{$\begin{array}{l}\text { Depolarization } \\
(\mathrm{mV})\end{array}$} & \multirow{2}{*}{$\begin{array}{l}\text { C-potential } \\
\text { decrease } \\
(\%)\end{array}$} & \multirow{2}{*}{$\begin{array}{l}\text { Depolarization } \\
\text { (mV) }\end{array}$} & \multirow{2}{*}{$\begin{array}{l}\text { C-potential } \\
\text { decrease } \\
(\%)\end{array}$} \\
\hline Ions & $\mathrm{pH}$ & & & & \\
\hline Normal & 7.4 & $0.38 \pm 0.07(10)$ & $20.4 \pm 2.7(10)$ & $0.95 \pm 0.10(18)$ & $35.0 \pm 2.6(18)$ \\
\hline $\mathrm{Cl}$-free ${ }^{a}$ & 7.4 & $0.62 \pm 0.18(2)$ & $23.2=$ & 1.10 & 11.4 \\
\hline $\mathrm{Na}$-free & 7.4 & $0.08 \pm 0.05$ & - & $0.26 \pm 0.09$ & - \\
\hline $\mathrm{Na}-, \mathrm{Cl}$-free & 7.4 & 0.00 & - & 0.10 & - \\
\hline Normal & 6.5 & $0.36 \pm 0.06(5)$ & $25.8 \pm 4.4(5)$ & $1.92 \pm 0.10$ & $55.1 \pm 1.8(32)$ \\
\hline Cl-free & 6.5 & - & - & $1.72 \pm 0.31(4)$ & $49.6 \pm 9.2(4)$ \\
\hline Na-free & 6.5 & - & - & $0.30 \pm 0.09(8)$ & - \\
\hline $\mathrm{Na}-, \mathrm{Cl}$-free & 6.5 & - & - & $0.10 \pm 0.05$ & - \\
\hline
\end{tabular}

Values are mean \pm SEM; the number of experiments is given in parentheses.

${ }^{a}$ Five minute exposure to $\mathrm{PDBu}$ 
(3)
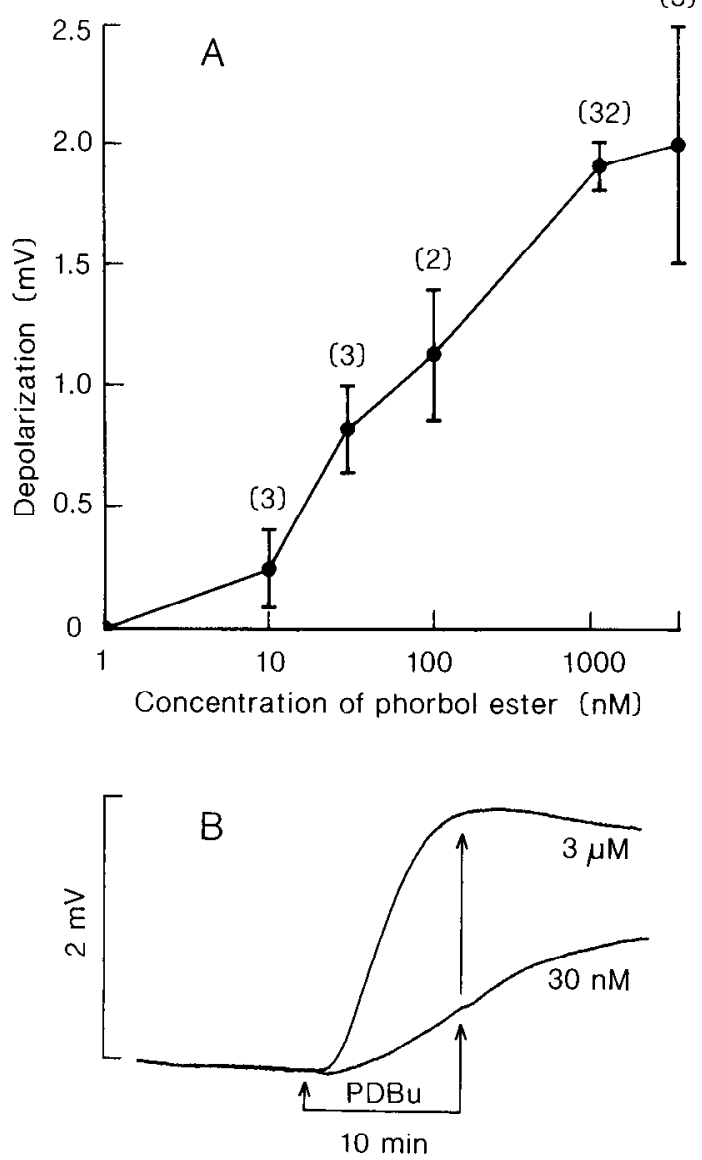

Figure 3. A, The relationship between concentration of PDBu in the bathing medium (pH 6.5) and the depolarization at the end of a $10 \mathrm{~min}$ exposure to the ester. Each point represents a mean value \pm SEM, the number of experiments being given in parentheses. $B$. Superimposed records of the responses to $10 \mathrm{~min}$ exposures to $30 \mathrm{nM}$ and $3 \mu \mathrm{MPDBu}$.

0.05 ; the PDBu-induced depolarization of $1-2 \mathrm{mV}$ observed experimentally (see Table 1) therefore implies an actual depolarization of $20-40 \mathrm{mV}$. However, fibers may well vary in their sensitivity to $\mathrm{PDBu}$, and it is possible that the remaining action potential is contributed by fibers that are relatively resistant to depolarization.

\section{Ionic mechanisms}

In principle, the ionic mechanism underlying the PDBu-induced depolarization could be one of the following: an increase in calcium permeability; an increase in chloride permeability; a decrease in potassium permeability; or an increase in sodium permeability. An inhibition of electrogenic sodium extrusion could not account for such a large and rapid depolarization (see Rang and Ritchie, 1968).

\section{Calcium, chloride and potassium}

The first 3 possibilities were eliminated by the following experimental results. First, as Figure 1 and Table 1 illustrate, the $\mathrm{PDBu}$-induced depolarization was much larger in calcium-free than in normal Locke's solution, so it is unlikely to be produced by calcium entry. Second, although the PDBu does apparently alter chloride conductance (see below), a change in chloride permeability is not a major factor, since a large PDBu-induced depolarization could be obtained in nerves washed in chloride-

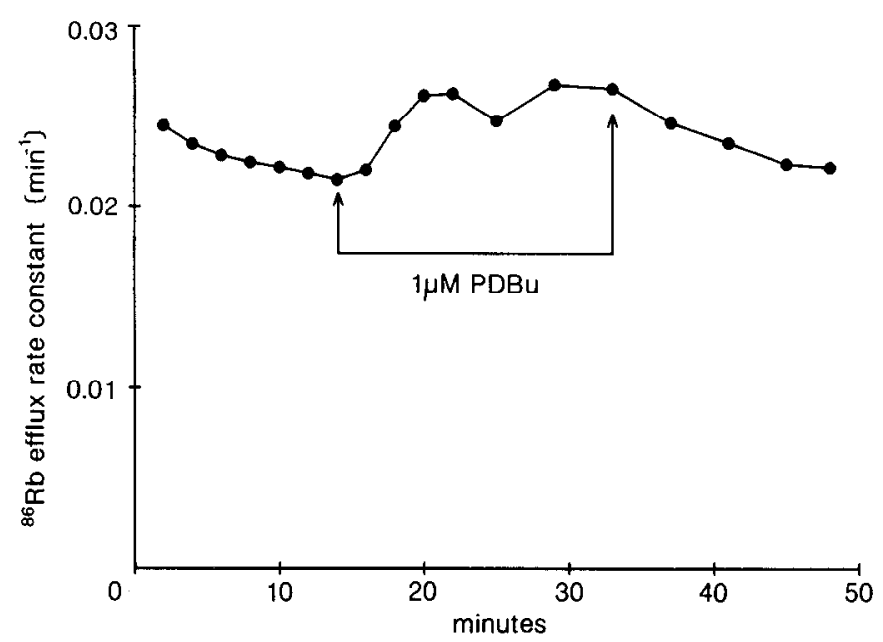

Figure 4. The rate constant of efflux of ${ }^{86} \mathrm{Rb}$ from rat vagus nerves before, during, and after exposure to $1 \mu \mathrm{M} \mathrm{PDBu} ; \mathrm{pH} 7.4$.

free Locke's solution for long enough to remove most of the intracellular chloride (Table 1). The possibility that PDBu-induced depolarization might have been due to a decrease in potassium permeability (Alkon et al., 1986; Farley and Auerbach, 1986) was tested by measuring ${ }^{86} \mathrm{Rb}$ efflux. A decrease in potassium permeability would be expected to be accompanied by a decrease in ${ }^{86} \mathrm{Rb}$ efflux from the $\mathrm{C}$-fibers. However, as Figure 4 shows, the rate constant of efflux of ${ }^{86} \mathrm{Rb}$ was increased on exposure to $1 \mu \mathrm{M} \mathrm{PDBu}$. This increase in ${ }^{86} \mathrm{Rb}$ efflux (which we believe to be a secondary response to the depolarization; see below) is not consistent with the depolarization's being a consequence of reduced potassium permeability.

\section{Sodium ions}

The elimination as the primary cause of the depolarization of changes in the permeability to calcium, chloride, or potassium ions strongly suggested the importance of an increased permeability to sodium ions. Two lines of evidence support this view.

In the first set of experiments, carried out in calcium-free solution to maximize the response to PDBu, the preparation was exposed at about $20 \mathrm{~min}$ intervals to sodium-free Locke's solution (sodium being replaced with $\mathrm{NMG}$ ) for $3-4$ min periods and the consequent repolarization of the fibers recorded (Fig. 5). After the nerve had been exposed to $1 \mu \mathrm{M} \mathrm{PDBu}$, the re-

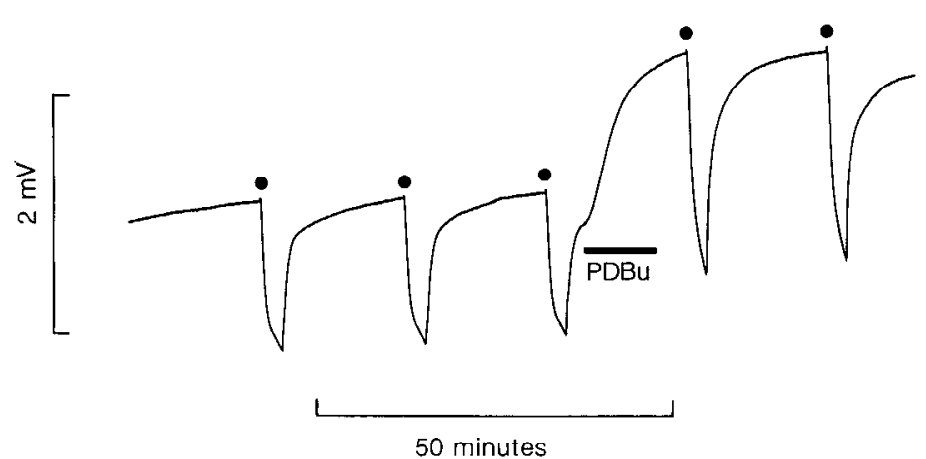

Figure 5. The effect on the resting potential of rat vagal C-fibers of 4 min exposures (dots) to sodium-free Locke's solution. The control bathing medium was calcium-free Locke's solution ( $\mathrm{pH} \mathrm{6.5).} \mathrm{At} \mathrm{the} \mathrm{solid}$ horizontal bar the preparation was exposed to $1 \mu \mathrm{M}$ PDBu. 

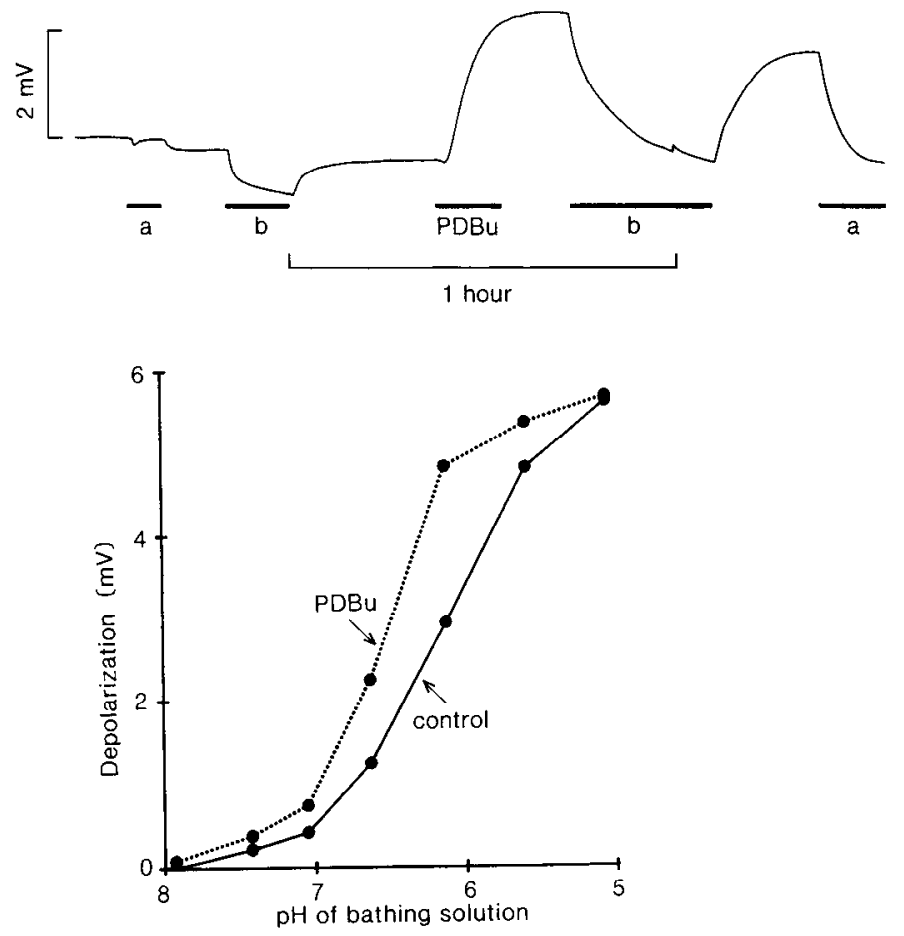

Figure 6. The effect of $\mathrm{pH}$ on the vagal response to $\mathrm{PDBu}$. Top, The effect of calcium and $\mathrm{pH}$ on the membrane potential of rat vagal $\mathrm{C}$-fibers before and after exposure to $\mathrm{PDBu}(1 \mu \mathrm{M})$ for $10 \mathrm{~min}$. At periods $a$ the preparation was switched from a calcium-free Locke's solution at pH 6.5 to one containing $2 \mathrm{~mm}$ calcium. At periods $b$ the $\mathrm{pH}$ of the bathing medium was increased from 6.5 to 7.4. Bottom. The relationship between resting potential and $\mathrm{pH}$ of the bathing medium in rat vagal C-fibers before (solid line) and after (dotted line) a $10 \mathrm{~min}$ exposure to $1 \mu \mathrm{MPDBu}$.

polarization produced by switching to sodium-free solution was considerably larger, being increased by an average factor of 1.74 $\pm 0.19(n=5)$. This suggested that the permeability to sodium had increased, and, since the other likely mechanisms could be rejected, we concluded that this was the major factor involved.

In other experiments, also in calcium-free solution, the mean amplitude of the PDBu-induced depolarization recorded in sodium-free solution was $0.26 \pm 0.09 \mathrm{mV}(n=5)$, compared with $0.95 \pm 0.10 \mathrm{mV}(n=18)$ in the presence of sodium.

Lithium ions can substitute for sodium in the generation of the action potential (Hodgkin and Katz, 1949), though they are extruded from the cell by the $\mathrm{Na} / \mathrm{K}$-pump much more slowly than is sodium (Keynes and Swan, 1959; Ritchie and Straub, 1980). PDBu was still able to induce depolarization in a Locke's solution in which all the sodium had been replaced by lithium, and this depolarization was reversed, as in the sodium Locke's solution, by calcium.

\section{Effect of $p H$}

For a time we were puzzled by a considerable variability in the magnitude of the response to PDBu. Examination of the factors responsible showed that the response was highly $\mathrm{pH}$-sensitive, being substantially enhanced at low $\mathrm{pH}$.

Under normal conditions the resting potential of vagal $\mathrm{C}$-fibers showed appreciable $\mathrm{pH}$ sensitivity, particularly over the range 5-7 (Fig. 6, bottom). The effect of $\mathrm{pH}$ on the resting potential took 5-10 min to equilibrate, and was quite reversible (Fig. 6, top). The equilibration time partly reflects the rate of diffusion into the tissue (see, for example, Colquhoun and Ritchie, 1972), but may also be due to the slowness of intracellular $\mathrm{pH}$ to respond to the extracellular $\mathrm{pH}$ change (see, for example, Evans and Thomas, 1984). The depolarization seen at acid $\mathrm{pH}$ was accompanied by the expected reduction in action potential amplitude. After exposure to $\mathrm{PDBu}(1 \mu \mathrm{M}$ for $10 \mathrm{~min})$, the effect of $\mathrm{pH}$ on the membrane potential became more pronounced, and depolarization occurred at less acidic $\mathrm{pH}$ values than in a normal nerve (Fig. 6, bottom). In 3 nerves perfused with calcium-free Locke's solution, the mean depolarization caused by reducing the $\mathrm{pH}$ from 7.4 to 6.5 was $0.38 \pm 0.05 \mathrm{mV}$; after treatment with $\mathrm{PDBu}$, the same $\mathrm{pH}$ change caused a mean depolarization of $1.48 \pm 0.15 \mathrm{mV}$. The enhancement of the depolarization produced by $\mathrm{PDBu}$ at $\mathrm{pH} 6.5$, compared with that at $\mathrm{pH} 7.4$, was verified in another series of experiments (Table 1). At $\mathrm{pH} 6.5$, in calcium-free solution, the average depolarization produced by $\mathrm{PDBu}(1 \mu \mathrm{M}$ for $10 \mathrm{~min})$ was $1.92 \pm 0.10 \mathrm{mV}$ $(n=32)$ and the decrease in amplitude of the C-fiber action potential was $55.1 \pm 1.8 \%$. The corresponding values at $\mathrm{pH} 7.4$ were $0.95 \pm 0.10 \mathrm{mV}$ and $35.0 \pm 2.6 \%(n=18)$. Because of the greater size and consistency of the results at pH 6.5, most of the experiments described below were performed in a calcium-free solution at $\mathrm{pH} 6.5$ unless otherwise noted.

Once developed, the large PDBu-induced depolarization at $\mathrm{pH} 6.5$ could be reversibly inhibited by switching to neutral $\mathrm{pH}$ (Fig. 6), suggesting that $\mathrm{pH}$ affects the behavior of the channels that are opened by $\mathrm{PDBu}$, rather than the phosphorylation reaction itself.

\section{Divalent cations}

It was noted earlier (Fig. 1) that the PDBu-induced depolarization was smaller in normal ( $2 \mathrm{~mm}$ calcium) Locke's than in calcium-free Locke's solution. Consistent with this, a brief application of $2 \mathrm{~mm}$ calcium to a nerve bathed in calcium-free solution, which had had little effect before treatment with $\mathrm{PDBu}$, also rapidly abolished the PDBu-induced depolarization (Fig. 6). As already stated, the PDBu-induced depolarization, once developed, normally persisted for at least $30 \mathrm{~min}$ after removal of the PDBu (see Figs. 1, 2). The repolarizing effect of calcium was equally marked at $\mathrm{pH} 6.5$ or $\mathrm{pH} 7.4$. This unexpected effect of calcium was investigated in more detail, and the effect of other divalent cations on the PDBu-induced depolarization was studied.

The onset of the calcium-induced repolarization was rapidwithin $15 \mathrm{sec}$ of the switch (corresponding to the dead-time of the perfusing system) - and the recovery of the resting potential toward its original value was substantial and complete within 5-10 min (Fig. 7A). However, when the bathing medium was switched back once more to calcium-free solution, the resting potential did not immediately return to the depolarized state, and such recovery from exposure to the $2 \mathrm{~mm}$ calcium solution as did occur was always slow and incomplete. Although the resting potential was restored close to its control level by $2 \mathrm{~mm}$ calcium, this was not accompanied by a corresponding recovery of the action potential.

Concentrations of calcium as low as $100-200 \mu \mathrm{M}$ produced repolarizations that were about half that produced by $2 \mathrm{~mm}$ calcium (Fig. $7 B$ ), though the effect was produced more slowly.

One possible explanation for the repolarizing effect of calcium is that it is able to open calcium-activated potassium channels (see Meech, 1978; Schwarz and Passow, 1983); another is that calcium is able to block the channel through which sodium is 


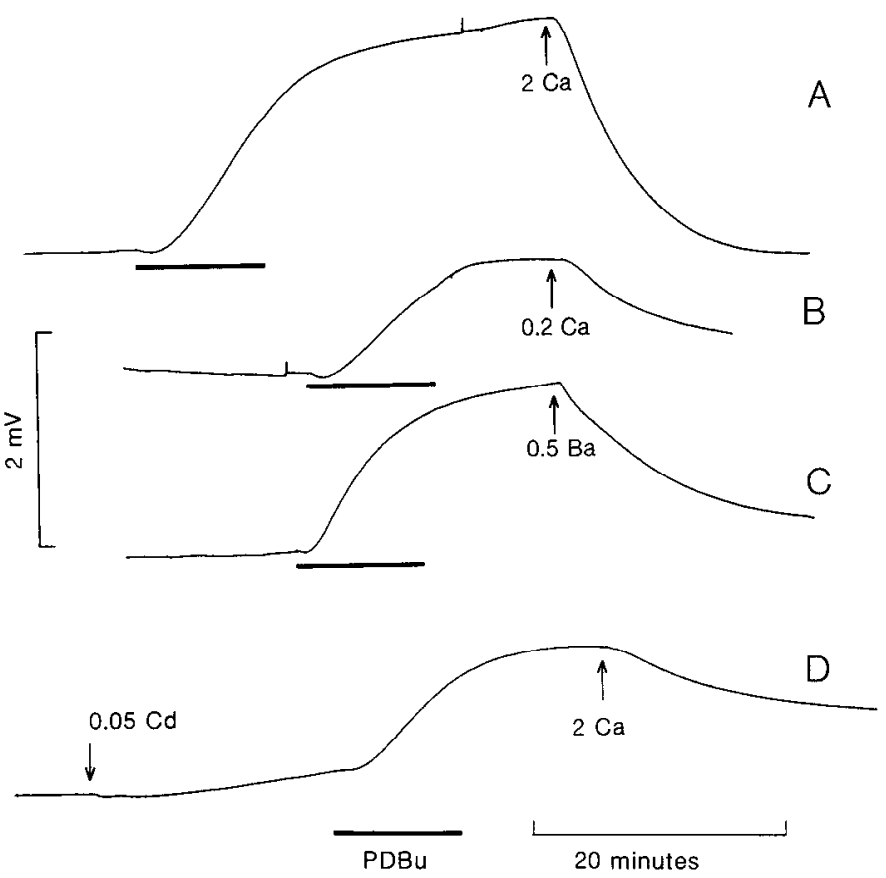

Figure 7. The effect of divalent cations on the phorbol-induced depolarization in rat vagal $\mathrm{C}$-fibers. Each nerve was exposed to PDBu (1 $\mu \mathrm{M})$ for $10 \mathrm{~min}($ bar $)$ in calcium-free Locke's solution at $\mathrm{pH}$ 6.5. At the arrows, the bathing medium was replaced by one containing: $(A) 2 \mathrm{mM}$ calcium; (B) $200 \mu \mathrm{M}$ calcium; (C) $500 \mu \mathrm{M}$ barium. In $D, 0.05 \mathrm{mM}$ cadmium was added at the first arrow, and remained throughout the experiment.

entering, analogous to the type of interaction reported for voltage-activated calcium channels in calcium-free solution (Almers and McCleskey, 1984; Almers et al., 1984; Lee and Tsien, 1984; Jmari et al., 1987). These 2 effects of calcium are known to show different patterns of activity among the various divalent cations. Barium, for example, interacts strongly with the calcium channel, but is ineffective in opening potassium channels (and actually blocks them). We therefore investigated the effect of a variety of divalent cations on the PDBu-induced depolarization. Barium and strontium were found to produce the same effect as calcium, at similar concentrations (see Fig. 7; Table 2). None of the other divalent cations tested $\left(\mathrm{Cd}^{2+}, 0.2 \mathrm{mM} ; \mathrm{Mg}^{2+}, 2 \mathrm{mM}\right.$; $\mathrm{Co}^{2+}, 1 \mathrm{~mm} ; \mathrm{Ni}^{2+}, 2 \mathrm{~mm} ; \mathrm{Mn}^{2+}, 0.5 \mathrm{~mm}$ ) or the trivalent cation $\mathrm{La}^{3+}(1 \mathrm{~mm})$ shared this ability (see Table 2$)$; most of them caused depolarization under control conditions. Though they did not themselves cause repolarization of the nerve after PDBu, some of these ions blocked or slowed the repolarizing effect of calcium (Fig. 7D, Table 2). For example, in the experiment shown in Figure $7 D$, which was carried out in the presence of $50 \mu \mathrm{M} \mathrm{Cd}^{2+}$, the repolarization produced by $2 \mathrm{~mm}$ calcium following a PDBu-induced depolarization was slower to develop than in a normal preparation (as in Figs. 6, 7). A measure of this slowing was obtained by estimating the size of the PDBuinduced depolarization at its plateau just before addition of 2 mM calcium and then measuring the percentage of this depolarization that had been reversed at the end of $5 \mathrm{~min}$ exposure to calcium in the presence of the blocking ion. In normal nerves, the potential recovered by $72 \pm 4 \%(n=11)$ at the end of the $5 \mathrm{~min}$ exposure to $2 \mathrm{~mm}$ calcium; exposure to a lower concentration (e.g., $100 \mu \mathrm{M}$ calcium) led to a smaller recovery $(19 \pm$ $10 \% ; n=3$ ). In the presence of divalent cations (and lanthanum), the fractional recovery was reduced (Table 2).
Table 2. Effect of various divalent cations and lanthanum on PDBuinduced depolarization

A. Percentage recovery (mean $\pm S E M$; number of experiments is given in parentheses) of membrane potential $5 \mathrm{~min}$ after adding test cation, following depolarization by $10 \mathrm{~min}$ exposure to $\mathrm{PDBu}(1 \mu \mathrm{M})$ in $\mathrm{Ca}-$ free solution at $\mathrm{pH} 6.5$

\begin{tabular}{llll} 
Test cation & $\begin{array}{l}\text { Concentration } \\
(\mathrm{mM})\end{array}$ & \multicolumn{2}{l}{ \% Recovery } \\
\hline $\mathrm{Ca}$ & 0.1 & $14 \pm 14(2)$ \\
& 0.2 & $38 \pm 5(2)$ \\
& 0.4 & $53 \pm 9(5)$ \\
$\mathrm{Ba}$ & 2.0 & $72 \pm 4(1)$ \\
& 0.5 & 46 & $(1)$ \\
$\mathrm{Sr}$ & 2.0 & 65 & $(1)$ \\
$\mathrm{Mg}$ & 1.0 & 59 & $(1)$ \\
$\mathrm{Cd}$ & 2.0 & 0 & \\
$\mathrm{Co}$ & 0.2 & $0^{a}$ & \\
$\mathrm{Ni}$ & 1.0 & $0^{a}$ & \\
$\mathrm{Mn}$ & 2.0 & $0^{a}$ & \\
$\mathrm{La}$ & 0.5 & $0^{a}$ &
\end{tabular}

B. Effect of cations on the percentage repolarization (mean $\pm \mathrm{SEM}$; number of experiments is given in parentheses) produced by addition of $2 \mathrm{~mm} \mathrm{Ca}$ for $5 \mathrm{~min}$, following PDBu-induced depolarization; the test cation was applied for about $5 \mathrm{~min}$ before the addition of 2 mм Ca

\begin{tabular}{llll} 
Test cation & $\begin{array}{l}\text { Concentration } \\
(\mathrm{mm})\end{array}$ & $\begin{array}{l}\text { \% Repolarization } \\
\text { by } 2 \mathrm{mM} \mathrm{Ca}\end{array}$ \\
\hline None & & $72 \pm 4(11)$ \\
$\mathrm{Cd}$ & 0.05 & 41 & $(1)$ \\
& 0.1 & $37 \pm 6(3)$ \\
$\mathrm{Co}$ & 0.2 & $19 \pm 10(2)$ \\
$\mathrm{Ni}$ & 1.0 & 36 & $(1)$ \\
& 1.0 & 36 & $(1)$ \\
$\mathrm{Mn}$ & 2.0 & 41 & $(1)$ \\
$\mathrm{La}$ & 0.5 & 26 & $(1)$ \\
& 0.05 & $37 \pm 21(2)$ \\
& 0.1 & 0 & $(1)$
\end{tabular}

"Thesc cations causcd appreciable depolarization to a similar degree both under control conditions and after PDBu.

Taken together, these results argue against each of the 2 explanations that we had considered. Thus, the effect of intracellular calcium in opening potassium channels is known not to be shared, or only very weakly, by barium and strontium (see Schwarz and Passow, 1983), both of which were able to repolarize nerves after PDBu treatment. Measurement of ${ }^{86} \mathrm{Rb}$ efflux (see below; Fig. 4) also gave results incompatible with the theory that calcium was acting by increasing the conductance to potassium ions.

\section{Channel blockers}

A variety of channel-blocking agents, in addition to divalent cations, were tested to see whether they either reversed the PDBu-induced depolarization or blocked the repolarizing effect of calcium. The following were ineffective in these respects (Fig. 8): tetrodotoxin $(1 \mu \mathrm{M})$, amiloride $(1 \mathrm{mM})$, nifedipine $(10 \mu \mathrm{M})$, verapamil $(50 \mu \mathrm{M})$, and diltiazem $(1 \mathrm{mM})$. Similarly, blockers of calcium-activated channels (quinine, $1 \mathrm{~mm}$; tubocurarine, 


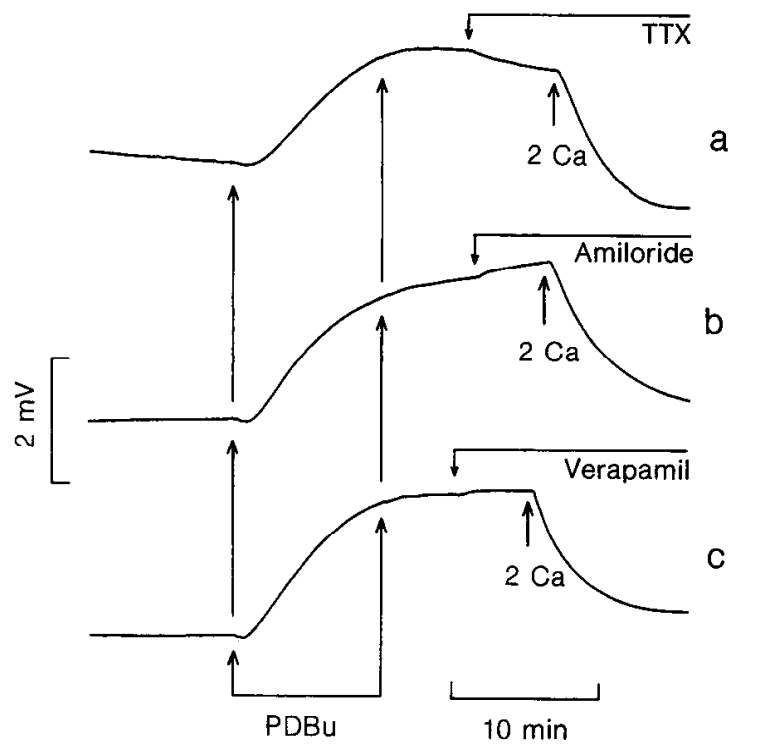

Figure 8. The effect of channel-blocking agents on the phorbol-induced depolarization of rat vagal $\mathrm{C}$-fibers. PDBu $(1 \mu \mathrm{M})$ was applied for 10 min in calcium-free Locke's solution at $\mathrm{pH}$ 6.5. At the arrow, $2 \mathrm{~mm}$ calcium was applied. Also present, prior to the addition of calcium, were (a) $1 \mu \mathrm{M}$ tetrodotoxin (TTX); (b) $200 \mu \mathrm{M}$ amiloride; and (c) $50 \mu \mathrm{M}$ verapamil.

$100 \mu \mathrm{M}$; apamin, $50 \mathrm{nM}$ ) neither reversed the depolarization nor interfered with the action of calcium (Fig. 9).

Although none of the conventional sodium- or calcium-channel blocking agents reduced the PDBu-induced depolarization, 4-aminopyridine, which blocks many different kinds of potassium conductance, especially the delayed rectifier potassium conductance (see Hille, 1984), did modify the response. In the experiment shown in Figure $10 a$, 4-aminopyridine ( $1 \mathrm{~mm}$ ) caused a depolarization, presumably due to the shutting of potassium channels, and there was an increase in amplitude and broadening of the C-fiber action potential. In the presence of 4-aminopyridine, the PDBu-induced depolarization developed more rap-

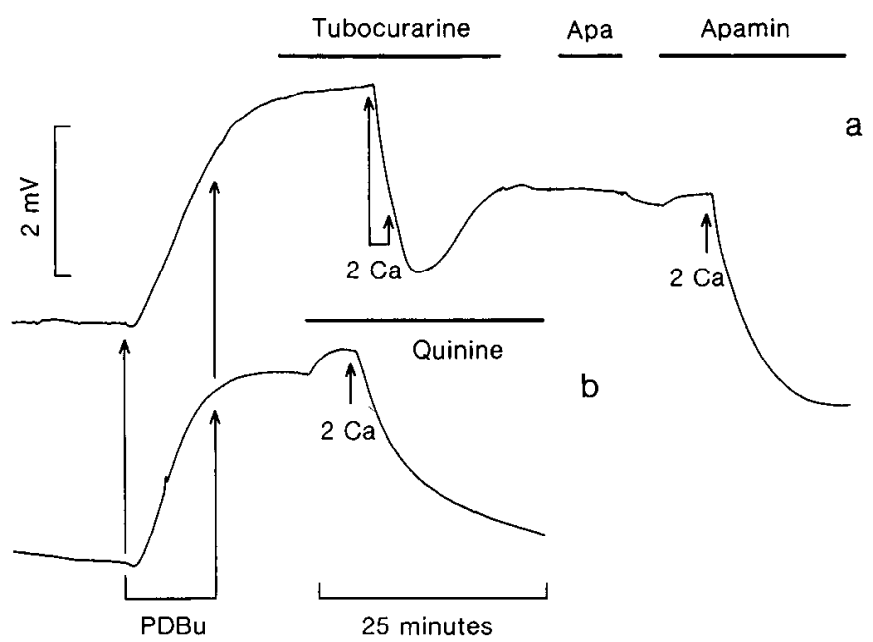

Figure 9. The effect of agents that block some calcium-activated potassium channels on the phorbol-induced depolarization of rat vagal C-fibers. At the end of each record, the bathing medium (calcium-free Locke's solution, pH 6.5) was replaced by one containing $2 \mathrm{mM}$ calcium. At the bars above each record were added $(a) 100 \mu \mathrm{M}$ tubocurarine and $50 \mathrm{~nm}$ apamin; (b) $1 \mathrm{~mm}$ quinine hydrochloride. Calcium ( $2 \mathrm{~mm}$ ) was also present for a brief period, as indicated.

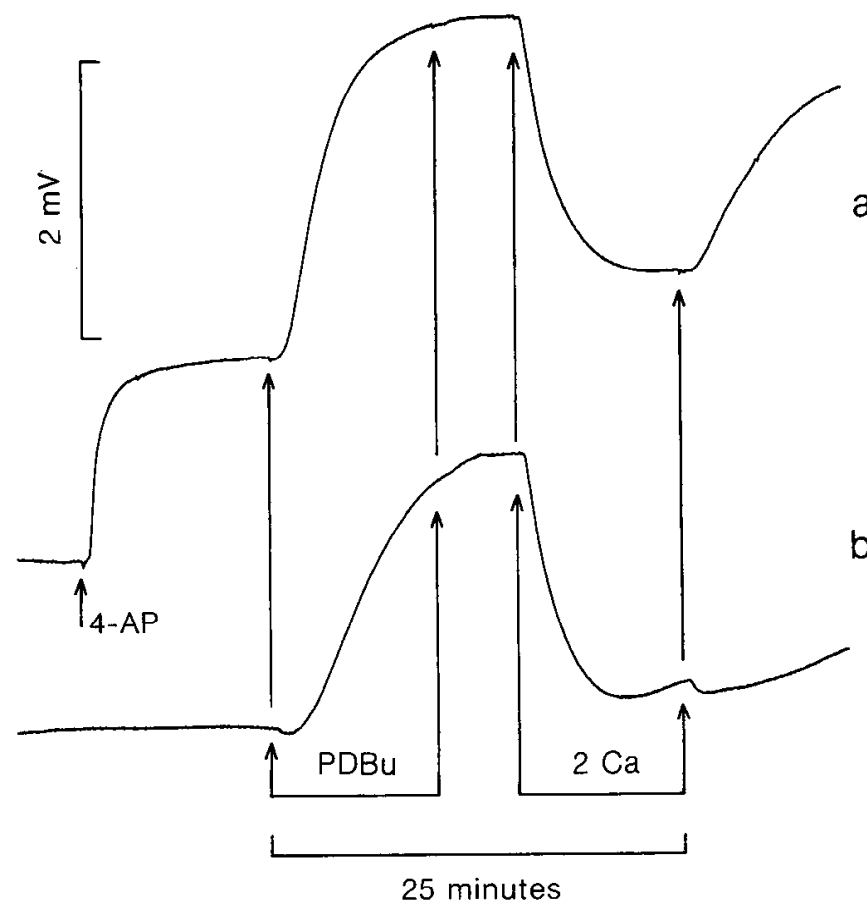

Figure 10. The effect of 4-aminopyridine on the PDBu-induced depolarization of rat vagal $\mathrm{C}$-fibers. As indicated, the phorbol ester (PDBu, $1 \mu \mathrm{M})$ and calcium ( $2 \mathrm{mM}$ ) were added to the bathing medium (calciumfree Locke's solution, $\mathrm{pH}$ 6.5). The records were taken in the presence (a) and absence (b) of $1 \mathrm{~mm}$ 4-aminopyridine (added at the arrow).

idly than normally and reached its plateau during the $10 \mathrm{~min}$ period of exposure to $\mathrm{PDBu}$. The repolarization following addition of $2 \mathrm{~mm}$ calcium was also more rapid than in the absence of 4-aminopyridine. Thus, after $5 \mathrm{~min}$ exposure to $2 \mathrm{~mm}$ calcium, there was a recovery of $83 \pm 3 \%(n=4)$, as compared to the value of $72 \pm 4 \%(n=11)$ in normal Locke's solution. Furthermore, in contrast to the results obtained in the absence of 4-aminopyridine (Fig. 13b), on reverting to calcium-free Locke's solution, the membrane potential quickly depolarized once more.

\section{Chloride ions}

As indicated in Table 1, replacement of the chloride of Locke's solution by the impermeant organic anion gluconate did not substantially reduce the PDBu-induced depolarization. Nevertheless, the depolarization does not appear to be solely due to an increase in sodium conductance, for removal of external sodium did not completely abolish the depolarization, but only reduced it (from $0.95 \pm 0.1 \mathrm{mV}$ to $0.26 \pm 0.09 \mathrm{mV}$ at $\mathrm{pH} \mathrm{7.4}$, and from $1.92 \pm 0.10 \mathrm{mV}$ to $0.30 \pm 0.09 \mathrm{mV}$ at $\mathrm{pH} 6.5$; see Table 1). However, replacement of chloride by gluconate, in sodium- and calcium-frcc Locke's solution, further reduced the PDBu-induced depolarization (at $\mathrm{pH} 6.5$ ) to $0.10 \pm 0.05 \mathrm{mV}$ $(n=5)$, a response that was difficult to measure with certainty on account of slow drifts in the recording. We conclude that PDBu causes a change in chloride permeability, presumably an increase, since GABA is known to cause C-fiber depolarization by increasing the chloride permeability (Brown and Marsh, 1978).

The chloride-mediated response to $\mathrm{PDBu}$, recorded in sodium-free solution, differed in certain respects from the response recorded in the presence of sodium. One important difference was that the repolarizing effect of calcium did not occur. Thus, in the experiment shown in Figure 11, addition of calcium after 
exposure to PDBu in sodium-free solution caused a further depolarization of the nerve (compare Figs. 7 and 1).

The effect of $\mathrm{pH}$ changes on the membrane potential was also much smaller in the absence of sodium. Before application of $\mathrm{PDBu}$, switching from $\mathrm{pH} 7.4$ to $\mathrm{pH} 6.5$ caused a depolarization of $0.20 \pm 0.03 \mathrm{mV}(n=3)$ in sodium-free solution. In 2 nerves (data not shown) in which PDBu caused depolarizations of 0.15 and $0.43 \mathrm{mV}$, respectively (sodium-free; $\mathrm{pH} 6.5$ ), the same $\mathrm{pH}$ switch after PDBu treatment produced only the same change in membrane potential $(0.2 \mathrm{mV}$ in each case $)$ as it had before PDBu (see Fig. 6, showing the enhanced dependence of the membrane potential on $\mathrm{pH}$ following $\mathrm{PDBu}$ treatment in sodium-containing solution). We conclude that the ability of calcium and $\mathrm{pH}$ to regulate the $\mathrm{PDBu}$-induced permeability change is confined to the sodium permeability component of the response, and that the smaller chloride component is not, or is much less, sensitive to calcium ions or protons.

\section{Cation fluxes}

We have measured, in parallel experiments, the effect of PDBu on both the ${ }^{86} \mathrm{Rb}$ efflux (as a marker for potassium efflux) and ${ }^{14} \mathrm{C}$-guanidinium efflux (as a marker for sodium efflux).

Figure 12 shows the effect of $1 \mu \mathrm{M}$ PDBu on the efflux of these 2 cations in calcium-free Locke's solution at $\mathrm{pH}$ 6.5. As Figure $12 \mathrm{~A}$ illustrates, a 10 min exposure to $\mathrm{PDBu}$ causes a large increase in ${ }^{86} \mathrm{Rb}$ efflux, which rapidly subsides to near the original baseline even though the PDBu is still present.

Exposure to high-potassium Locke's solution (sodium completely replaced by $160 \mathrm{~mm}$ potassium) evokes a large efflux of ${ }^{86} \mathrm{Rb}$, which decreases gradually to a fairly steady level within about $1 \mathrm{hr}$; at this time, addition of PDBu causes no increase in the rate of efflux (Fig. 12A). The absence of any PDBu-induced change in ${ }^{86} \mathrm{Rb}$ efflux in nerves that are fully depolarized suggests that the response seen normally may be secondary to the depolarization caused by PDBu. It is, however, possible that the increased ${ }^{86} \mathrm{Rb}$ efflux represents a flux through PDBu-induced channels that are inactivated by prolonged depolarization. The response was unaffected by $1 \mathrm{~mm}$ 4-aminopyridine (data not shown).

Figure $12 B$ shows the corresponding fluxes of ${ }^{14} \mathrm{C}$-guanidinium in parallel experiments. Again, exposure to $\mathrm{PDBu}$ in calcium-free solution causes a marked, but not maintained, increase in efflux; as expected from the depolarization experiments, this response is considerably larger at $\mathrm{pH} 6.5$ than at $\mathrm{pH} 7.4$. In high-potassium solution, the response almost disappears, though there is consistently a small, sustained increase (by 13.9

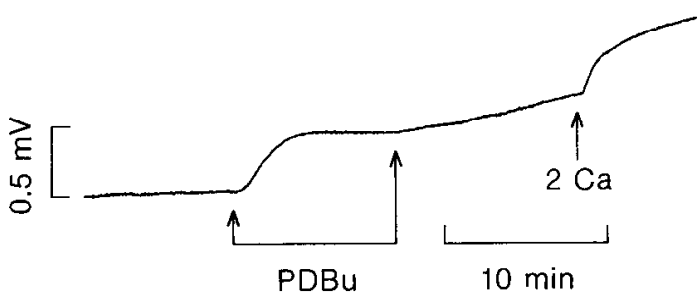

Figure 11. The response to a $10 \mathrm{~min}$ exposure to $1 \mu \mathrm{M} \mathrm{PDBu}$ and subsequent exposure to calcium ( $2 \mathrm{mM}$ ) of rat vagal C-fibers in sodiumfree, calcium-free Locke's solution at pH 6.5.

$\pm 4.8 \% ; n=3$ ) in efflux caused by $\mathrm{PDBu}$, which may reflect its action in opening sodium channels. Replacement of sodium by $(+)-N$-methylglucamine, which reduces, but does not completely abolish, the depolarization in response to PDBu (Table 1), similarly reduces the guanidinium efflux response (Table 3 ).

Addition of tetrodotoxin $(1 \mu \mathrm{M})$ slightly reduces both the resting efflux and the response to PDBu (Fig. 13A). 4-Aminopyridine ( $1 \mathrm{~mm}$ ) affects only the resting efflux, increasing it slightly (data not shown). Exposure of the nerve to $50 \mathrm{~mm}$ potassium (replacing $50 \mathrm{~mm}$ sodium) produces an increase in guanidinium efflux of similar magnitude to that produced by PDBu (Fig. 13B), but unlike the PDBu effect, the increase is sustained during a 5 or $10 \mathrm{~min}$ period of exposure to the raised potassium concentration, and is inhibited by about $60 \%$ in the presence of $1 \mu \mathrm{M}$ tetrodotoxin. The increase in guanidinium efflux produced by $50 \mathrm{~mm}$ potassium is not diminished after PDBu treatment (Fig. 13C), showing that the decline in efflux that occurs during treatment with $\mathrm{PDBu}$ is not the result of $\mathrm{PDBu}$-induced inactivation of voltage-sensitive channels. As Figure 12 shows, when $2 \mathrm{~mm}$ calcium is added to the bathing solution after exposure of the nerve to $\mathrm{PDBu}$, the efflux of both ${ }^{86} \mathrm{Rb}$ and ${ }^{14} \mathrm{C}$-guanidinium decreases concomitantly with the repolarization discussed above (Figs. 6-9).

It seems highly likely that most of the increase in guanidinium and rubidium efflux is secondary to the depolarization produced by $\mathrm{PDBu}$, and occurs partly as a result of the opening of voltagesensitive channels and partly as a result of the increased electrochemical gradient for cation efflux. The naturc of the channcls underlying these passive changes in efflux has not been examined further. Two points are noteworthy, however. First, in potassium-depolarized nerves, PDBu still evokes a small, sustained increase in guanidinium, but not in rubidium, efflux, and this response is curtailed by $2 \mathrm{~mm}$ calcium. This response could not have been secondary to changes in membrane potential, and

Table 3. Rate constants of efflux of ${ }^{86} \mathrm{Rb}$ and ${ }^{14} \mathrm{C}$-guanidinium from desheathed rat vagus nerves before

$\left(k_{\mathrm{r}}\right)$ exposure to $1 \mu \mathrm{M} \mathrm{PDBu}$, and the peak value reached in the presence of $\mathrm{PDBu}\left(k_{\mathrm{PDBu}}\right)$

\begin{tabular}{|c|c|c|c|c|c|}
\hline \multicolumn{2}{|c|}{ Test solution } & \multirow[b]{2}{*}{$n$} & \multirow{2}{*}{$\begin{array}{l}k_{\mathrm{r}} \\
\left(\min ^{-1}\right)\end{array}$} & \multirow{2}{*}{$\begin{array}{l}k_{\mathrm{PDBu}} \\
\left(\mathrm{min}^{-1}\right)\end{array}$} & \multirow{2}{*}{$\begin{array}{l}\text { Increase } \\
(\%)\end{array}$} \\
\hline Ions & $\mathrm{pH}$ & & & & \\
\hline \multicolumn{6}{|l|}{${ }^{86} \mathrm{Rb}$ efllux } \\
\hline \multirow[t]{2}{*}{ Normal } & 7.4 & 4 & $0.0205 \pm 0.0018$ & $0.0287 \pm 0.0047$ & $37.5 \pm 10.4$ \\
\hline & 6.5 & 5 & $0.0136+0.0004$ & $0.0339 \pm 0.0046$ & $151.4 \pm 37.2$ \\
\hline \multicolumn{6}{|c|}{${ }^{14} \mathrm{C}$-guanidinium efflux } \\
\hline \multirow[t]{2}{*}{ Normal } & 7.4 & 3 & $0.0061 \pm 0.0001$ & $0.0090 \pm 0.0003$ & $46.2 \pm 6.4$ \\
\hline & 6.5 & 7 & $0.0055 \pm 0.0009$ & $0.0249 \pm 0.0031$ & $376.0 \pm 61.7$ \\
\hline \multirow[t]{2}{*}{ Na-free } & 7.4 & 3 & $0.0092 \pm 0.0011$ & $0.0136 \pm 0.0031$ & $43.7 \pm 17.9$ \\
\hline & 6.5 & 3 & $0.0071 \pm 0.0009$ & $0.0084 \pm 0.001$ & $16.9 \pm 0.8$ \\
\hline
\end{tabular}



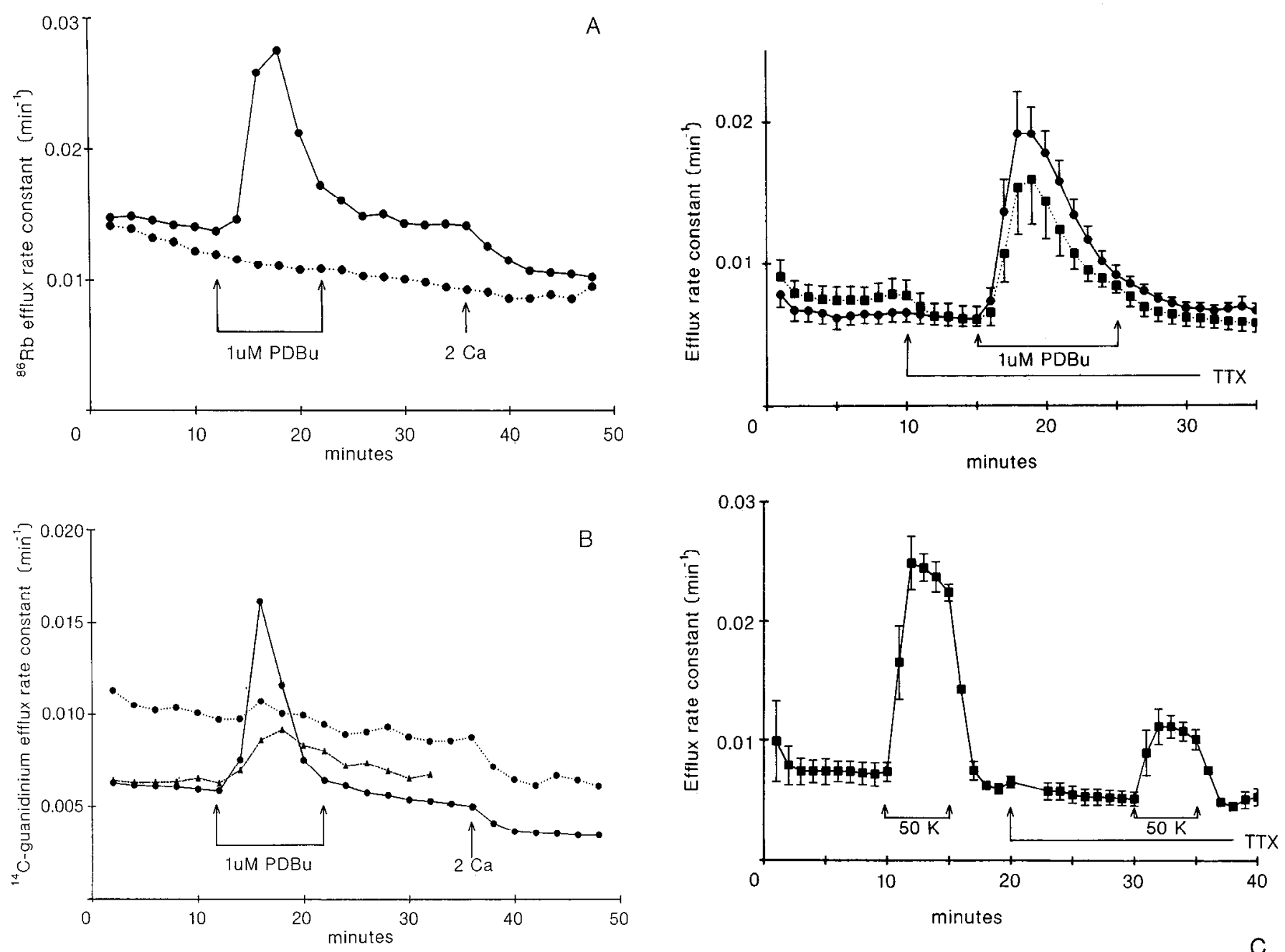

Figure 12. The rate constants of efflux of ${ }^{86} \mathrm{Rb}(A)$ and ${ }^{14} \mathrm{C}$-guanidinium $(B)$ from rat vagus nerves in calcium-free Locke's solution at $\mathrm{pH} 6.5$ (circles, solid line), and in a similar solution in which the sodium had been replaced by potassium. In $B$, the response in calcium-free Locke's solution at $\mathrm{pH}>4$ is also slower (triangles).

may represent the primary action of PDBu in opening a cation channel. Second, addition of $2 \mathrm{~mm}$ calcium atter exposure of the nerve to PDBu causes a decrease, rather than an increase, in rubidium efflux. This provides further evidence (see above section) that the repolarizing effect of calcium is not due to an increase in potassium conductance.

\section{Discussion}

The main conclusion of this study is that activation of protein kinase $\mathrm{C}$ in the nonmyelinated sensory fibers of the vagus nerve produces a strong depolarization that results mainly from an increase in sodium conductance. Most of the nerve membrane in the vagus is associated with nonmyelinated fibers, which must have contributed to the large depolarization that was recorded. Even complete depolarization of the myelinated fibers would not have shunted the $\mathrm{C}$-fiber action potential by more than $50 \%$ (Table 1). It is, however, possible that the observed reduction of the B-fiber action is due to shunting by the increased conductance of the $\mathrm{C}$-fibers, rather than a direct effect of PDBu on the B-fibers.

There is now a growing list of membrane channel responses attributed to phosphorylation of membrane proteins by kinase

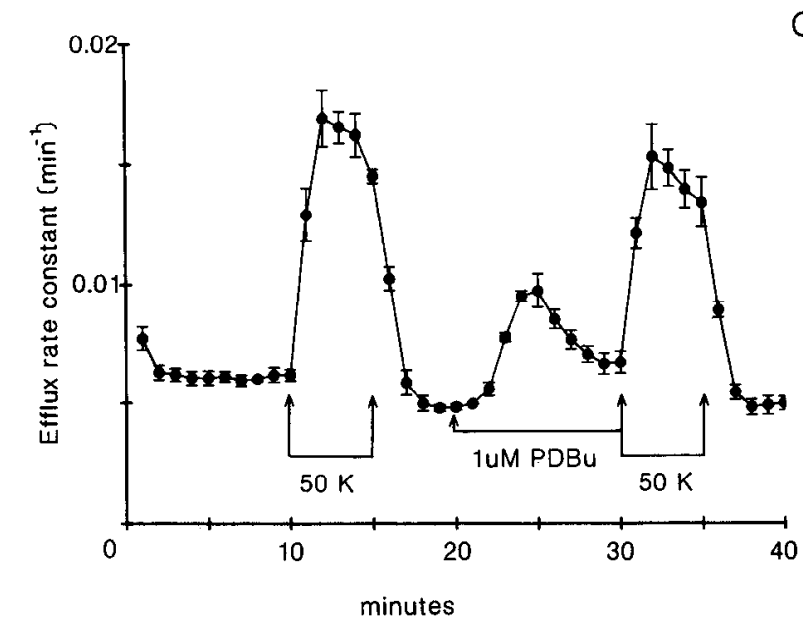

Figure 13. The rate constant of efflux of ${ }^{14} \mathrm{C}$-guanidinium from the rat vagus in calcium-free Locke's solution at pH 6.5. Bars show SEM values for several nerves. $A$, The effect of tetrodotoxin (TTX; $1 \mu \mathrm{M}$ ) on the response to PDBu. Circles, control nerves in the absence of TTX $(n=$ $9)$; squares, TTX added as indicated $(n=6) . B$, The effect of TTX (1 $\mu \mathrm{M})$ on the response to $\mathrm{K}$-induced depolarization. For the $5 \mathrm{~min}$ periods shown, the solution was changed to one with $50 \mathrm{~mm}$ added $\mathrm{KCl}$ (replacing $50 \mathrm{mM} \mathrm{NaCl}$ ). In the absence of TTX, the second response to $\mathrm{K}^{+}$averaged $85 \pm 2 \%(n=4)$ of the first response (not shown). $C$, Response to $\mathrm{K}^{+}$was unaffected by $10 \mathrm{~min}$ exposure of the nerve to PDBu. 
C (see reviews by Miller, 1986, 1987; Kaczmarek, 1987); so far, however, all of these reports have concerned potassium, calcium, or chloride channels that are activated either by depolarization or by a rise in intracellular calcium concentration. The response of vagal $\mathrm{C}$-fibers appears to be unusual in several respects: First, it involves predominantly an increased sodium conductance; second, the response is strongly inhibited by certain divalent cations, including calcium; and third, the effect shows a striking $\mathrm{pH}$ dependence.

\section{Involvement of protein kinase $C$}

The main evidence suggesting that the response is produced by kinase $\mathrm{C}$ activation, rather than by some ancillary pharmacological effect of PDBu is as follows: It is produced by the $\beta$-phorbol esters, PDBu and TPA, but not by $\alpha$-PDD, even at much higher concentration; the concentration range over which $\mathrm{PDBu}$ acts (threshold about $10 \mathrm{nM}$ ) corresponds with that for kinasc C activation (see references in Nishizuka, 1984, 1986); the effect at room temperature is slow to develop, with a lag period of 1$2 \mathrm{~min}$ before any response is seen, and a gradual buildup during the 10 min contact period that was normally used; and, finally, the effect, once developed, is long-lasting.

The slow onset and persistence of the development of the PDBu-induced depolarization, even after the ester has been removed, is clearly consistent with the idea (see Nishizuka, 1984) that the penetration of the ester intracellularly, and its subsequent activation of protein kinase $\mathrm{C}$, takes some time, and that, once activated by the phorbol ester, the protein kinase $\mathrm{C}$ remains activated. Whether the persisting depolarization on removal of the phorbol ester is a consequence of a persisting activation of protein kinase $\mathrm{C}$, or whether the channels, once phosphorylated, only slowly recover remains uncertain at the moment.

\section{Ionic mechanism of the response}

It is not feasible to use patch-clamp or microelectrode recording methods on C-fibers because of their small diameter (average, $0.6 \mu \mathrm{m}$; Keynes and Ritchie, 1965) and enveloping Schwann cells, which makes it difficult to establish unequivocally the ionic basis of the PDBu-induced effect. However, it seems clear that a major factor in the depolarization is an increase in the sodium conductance, for replacement of sodium by the impermeant cation NMG reduces the response by $60 \%$ in the presence of 2 $\mathrm{mm}$ calcium, and by $81 \%$ in the absence of calcium (Table 1 ).

Replacement of sodium by lithium, which is permeant in voltage-sensitive sodium channels (Hodgkin and Katz, 1949), does not prevent depolarization by PDBu. Lithium is not, or is only very slowly, transported by the $\mathrm{Na} / \mathrm{K}$ or $\mathrm{Na} / \mathrm{H}$ exchange mechanisms that transport sodium ions across the membrane (Keynes and Swan, 1959; Ritchie and Straub, 1980). The latter transport system has been reported to be activated by phorbol esters in some cells (see references in Nishizuka, 1986), but the ability of lithium to substitute for sodium suggests that it is not important as a factor in the response of the vagus to PDBu.

The response of the vagus evidently differs from that of another neuronally derived cell, namely the NG108-15 cell, in which phorbol esters also cause depolarization. Higashida and Brown (1986) have shown that this response results from inhibition of potassium conductances, in particular the M-current.

Supporting evidence for an increased cation conductance comes from the measurements of guanidinium efflux. PDBu causes a large, but transient, increase in guanidinium efflux, which is insensitive to tetrodotoxin. In contrast increased po- tassium concentration caused a sustained, tetrodotoxin-sensitive efflux, which is assumed to be due to noninactivating voltage-gated sodium channels. Potassium will, of course, depolarize all types of cell, and this efflux might not be due to C-fibers. Nevertheless, the transient nature of the response to PDBu, in spite of the persistent depolarization that it produces, suggests that it may exert an inhibitory effect on voltage-activated sodium channels, in addition to opening another type of cation channel-a conclusion that could partly explain its effect on the action potential (see Fig. 1).

Whether any of the increase in rubidium efflux that occurs following application of $\mathrm{PDBu}$ represents a primary effect of kinase $C$ on potassium channels, or whether it is all secondary to the depolarization, is not certain. Since, however, the PDBuinduced increase in rubidium eftlux was absent when the nerve was depolarized by high-potassium medium, it is likely that any direct effect of PDBu on potassium conductance is small.

Our results provide some evidence that chloride channels are opened by PDBu. A small, residual depolarization occurred when the bathing solution contained neither sodium nor calcium, and this was almost completely lost (see Table 1) if the nerve was exposed to chloride-free medium long enough to deplete the C-fibers of most of their intracellular chloride (Rang and Ritchie, 1968; Brown and Marsh, 1978). Madison et al. (1986) have reported a quite different effect of phorbol esters on the chloride conductance of hippocampal neurons. These cells possess a large depolarization-activated chloride conductance, which is inhibited by PDBu. An interesting feature of the chloride component of the vagal response (i.e., the depolarization occurring in sodium-free, chloride-containing solution) was that it did not show the pronounced sensitivity to calcium and $\mathrm{pH}$ that characterizes the PDBu effect recorded in normal Locke's solution.

There is, of course, no reason to think that the conductance changes that we have observed are the only effects produced. Indeed, the inhibition of the compound action potential by $\mathrm{PDBu}$, which is reversed only partially when the membrane potential is restored by application of calcium, and the transient nature of the increase in guanidinium efflux evoked by PDBu may well reflect an action on voltage-sensitive sodium channels, but we have not studied this further.

\section{The action of divalent cations}

The effect of the divalent cations was surprising, both insofar as the depolarization produced by PDBu was greater in calciumfree than in normal Locke's solution (Table 1), and insofar as calcium, but not most other divalent cations, exerted a repolarizing action on PDBu-depolarized nerves.

How might the ability of calcium to reverse the PDBu-induced depolarization be explained? The 3 cations that produce this effect-namely, calcium, strontium, and barium-are all known to be permeant in voltage-sensitive calcium channels (see Hille, 1984; Carbone and Lux, 1987); in contrast, cations that are known to block calcium channels without passing through them, such as cadmium, cobalt, nickel, magnesium, manganese, and lanthanum, fail to cause repolarization, and in some cases inhibit the repolarizing effect of calcium. We conclude that calcium, strontium, and barium probably act intracellularly to produce the repolarization, and that their entry is inhibited to a greater or lesser extent by other divalent cations and by lanthanum. The inability of any of the organic calcium-channel blockers to prevent the effect of calcium suggests that it is not 
gaining access to the cytosol via normal voltage-sensitive calcium channels; and it is therefore likely that the route of entry is through a channel that may appear as a consequence of the action of kinase $\mathrm{C}$. The inward current carried by calcium through this channel is presumably small, so that the net effect of adding calcium is to reduce the depolarizing current.

Two possibilities that may account for the repolarization associated with calcium entry were mentioned earlier-namely, the opening of calcium-activated potassium channels, and the block by calcium of the PDBu-activated sodium conductance. Additional possibilities are that calcium ions inhibit protein kinase C-mediated protein phosphorylation, or facilitate dephosphorylation.

Several pieces of evidence argue against the repolarization's being due to increased potassium conductance. Barium and strontium are both effective in causing repolarization, but barium does not activate calcium-activated potassium channels, and strontium does not (Moolenar and Spector, 1979a, b) or docs so only very wcakly (Gorman and Hermann, 1979). Also, a number of agents reported to block calcium-activated potassium channels, such as apamin (Banks et al., 1979; Pennefather et al., 1985), tubocurarine (Nohmi and Kuba, 1984; Higashida and Brown, 1986), and quinine (Cherubini et al., 1984), were found to have no effect on the repolarization produced by calcium. Finally, addition of calcium after PDBu treatment caused a decrease, rather than an increase, in the rate of ${ }^{86} \mathrm{Rb}$ efllux.

Blockage of cation channels by divalent cations acting from the inside of the membrane is not well-documented. There is evidence that voltage-sensitive calcium channels are inactivated by a rise in cytosolic free calcium, an effect that is not produced by barium or strontium (see Schwarz and Passow, 1983). Very little is known of the mechanism involved in this effect, and it is possible that a similar process could underlie the switch-off of the PDBu-induced cation conductance.

An inhibitory effect of calcium on protein kinase $\mathrm{C}$ is highly unlikely, since much biochemical evidence shows that kinase $\mathrm{C}$, on the contrary, requires calcium as a co-factor (see Nestler and Greengard, 1984; Nishizuka, 1986). Calcium-activated phosphoprotein phosphatases in neural tissue are well-documented (see Nestler and Greengard, 1984). One of these, calcineurin, is strongly activated by several divalent cations, including barium and strontium (Wolff and Sved, 1985), so it is possible that these ions cause repolarization by activating a phosphatase, thus reversing the effect of the kinase $C$. The failure of calcium to reverse the small, $\mathrm{PDBu}$-induced depolarization that occurs in sodium-free solution, or the inhibition of the action potential, somewhat favors the view that it is acting at the channel level, rather than by promoting phosphatase activity, since the latter action might be expected to reverse all of the effects; however, on the basis of the present experiments, we cannot distinguish with any certainty between channel block and phosphatase activation as mechanisms underlying the repolarizing effect of calcium.

\section{The effect of $p H$}

The membrane potential of normal C-fibers is unusually $\mathrm{pH}$ dependent, being strongly depolarized when the $\mathrm{pH}$ is reduced below 7 (Tig. 4). The depolarizing effect of low pI is not seen in sodium-free solution, so it presumably reflects an increased sodium permeability. After PDBu treatment, the $\mathrm{pH}$ dependence of the membrane potential is accentuated, and switching the $\mathrm{pH}$ from 6.5 to 7.4 causes a reversible repolarization of the nerve (Fig. 6). The small, PDBu-induced depolarization that occurs in sodium-free solution is not reversed by raising the $\mathrm{pH}$. Thesc results suggest that $\mathrm{pH}$ is affecting the gating of a sodium channel. In this connection, the recent study of Konnerth et al. (1987) is of interest; they show that, in chick sensory neurons, the calcium channel may exist in 2 mutually exclusive states: a normal state, in which the channel is a voltage-gated, calcium-permeable channel; and a transformed state, in which the channel is sodium-permeable and proton-gated. This latter state predominates when calcium is removed from the external medium or at low $\mathrm{pH}$, when calcium is displaced from the calcium-channel binding sites by protons - the very conditions found to produce the maximal response to phorbol esters in the rat vagus. It is possible, therefore, that phosphorylation of the calcium channel by phorbol esters induces a similar transformed state and causes the appearance of a sodium conductance that is sensitive to the external hydrogen ion concentration. A somewhat similar channel in sensory neurons has also been reported by Krishtal and Pidoplichko (1980, 1981), who showed that rapid shifts of external $\mathrm{pH}$ from 7.4 to 6.9 induce a $\mathrm{pH}$-dependent inward current in sensory neurons.

However, both channels described above (Krishtal and Pidoplichko, 1980; Konnerth et al., 1987) differ in important respects from that involved in our experiments. Thus, the current described by these authors is transient in nature, inactivating within seconds when the $\mathrm{pH}$ is stepped to a lower value, whereas the PDBu-induced depolarization persists for at least $30 \mathrm{~min}$. The channel described by Konnerth et al. (1987) also differs pharmacologically from the sodium channel postulated in the present experiments, for the former is blocked by the organic and inorganic calcium-channel blockers (diltiazem, cadmium, and nickel), whereas the latter is not, which makes it unlikely that the channel mediating the PDBu-induced sodium conductance is a transformed calcium channel.

\section{Physiological significance}

The mechanism by which a variety of chemical agents are able to excite nociceptive neurons is as yet unknown, but the present results raise the possibility that protein kinase $C$ might be involved in this process.

It is known that bradykinin, a potent pain-producing substance (see Keele and Armstrong, 1964), stimulates the formation of diacylglycerol in several different cell types, and thus causes activation of protein kinase $C$. Work in our laboratory has shown that this occurs in pure cultures of rat sensory neurons (Burgess et al., 1988) and that bradykinin produces depolarization, associated with an increased membrane conductance, in a proportion of these cells (Lindsay and Rang, 1987), an effect that can be mimicked by PDBu (Lindsay and Rang, 1988). It seems possible that the appearance of a pH-sensitive sodium channel as a result of protein kinase $\mathrm{C}$ activation might play a part in the activation of nociceptors by chemical stimuli. The strongly inhibitory effect of calcium on the vagal response would be an unexpected feature of a physiological mechanism, and it will be necessary to establish whether the action of bradykinin also shows this property.

\section{References}

Akers, R. F., D. M. Lovingers, P. A. Lolley, D. J. Linder, and A. Routtenberg (1986) Translocation of protein kinase C activity may mediate hippocampal long-term potentiation. Science 231: 587-589.

Alkon, D. L., M. Kubota, J. T. Neary, S. Naito, D. Coulter, and H.

Rasmussen (1986) C-Kinase activation prolongs $\mathrm{Ca}^{2+}$-dependent 
inactivation of $\mathrm{K}^{+}$channels. Biochem. Biophys. Res. Commun. 134: 1245-1253.

Almers, W., and E. W. McCleskey (1984) Non-selective conductance in calcium channels of frog muscle: Calcium selectivity in a singlefile pore. J. Physiol. (Lond.) 353: 585-608.

Almers, W., E. W. McCleskey, and P.T. Palade (1984) A non-selective cation conductance in frog muscle membrane blocked by micromolar external calcium ions. J. Physiol. (Lond.) 353: 565-583.

Armett, C. J., and J. M. Ritchie (1960) The action of acetylcholine on conduction in mammalian non-myelinated nerve fibres and its prevention by an anticholinesterase. J. Physiol. (Lond.) 152: 141158.

Banks, B. E., C. Brown, G. M. Burgess, G. Burnstock, M. Claret, T. M. Cocks, and D. H. Jenkinson (1979) Apamin blocks certain neurotransmitter-induced increases in potassium permeability. Nature 22: 415-417.

Brown, D. A., and S. Marsh (1978) Axonal GABA-receptors in mammalian peripheral nerve trunks. Brain Res. 156: 187-191.

Burgess, G. M., M. McNeill, and I. Mullaney (1988) Some actions of bradykinin on rat sensory neurones in culture are mediated by protein kinase C. J. Physiol. (Lond.) 398: 17 p.

Carbone, E., and H. D. Lux (1987) Kinetics and selectivity of a lowvoltage-activated calcium current in chick and rat sensory neurones. J. Physiol. (Lond.) 386: 547-570.

Cherubini, E., R. A. North, and A. Suprenant (1984) Quinine blocks a calcium-activated potassium conductance in mammalian enteric neurones. Br. J. Pharmacol. 83: 3-5.

Colquhoun, D., and J. M. Ritchie (1972) The kinetics of the interaction between tetrodotoxin and mammalian non-myelinated nerve fibres. Mol. Pharmacol. 8: 285-292.

DeRiemer, S. A., P. Greengard, and L. K. Kaczmarek (1985a) Calcium/phosphatidylserine/diacylglycerol-dependent protein phosphorylation in the Aplysia nervous system. J. Neurosci. 5: 2672-2676.

DeRiemer, S. A., J. A. Strong, K. A. Albert, P. Greengard, and L. K. Kaczmarek (1985b) Enhancement of calcium current in Aplysia by phorbol ester and protein kinase C. Nature 313: 313-316.

Di Virgilio, F., T. Pozzan, C. B. Wolheim, L. M. Vincentini, and J. Meldolesi (1986) Tumor promoter phorbol myristate acetate inhibits $\mathrm{Ca}^{2+}$ efflux through voltage-gated $\mathrm{Ca}^{2+}$ channels in two secretory cell lines, PC 12 and RINm5F. I. Biol. Chem. 261: 32-35.

Evans, M. G., and R. C. Thomas (1984) Acid influx into snail neurones caused by reversal of the normal $\mathrm{pH}_{\mathrm{i}}$ regulating system. J. Physiol. (Lond.) 346: 143-154.

Farley, J., and S. Auerbach (1986) Protein kinase C activation induces conduction changes in Hermissenda photoreceptors like those seen in associative learning. Nature 319: 220-223.

Gorman, A. L. F., and A. Hermann (1979) Internal effects of divalent cations on potassium permeability in molluscan neurons. J. Physiol. (Lond.) 296: 393-410.

Grega, D. S., M. A. Werz, and R. L. MacDonald (1987) Forskolin and phorbol esters reduce the same potassium conductance of mouse neurons in culture. Science 235: 345-348.

Higashida, H., and D. A. Brown (1986) Two phosphatidylinositide metabolites control two $\mathrm{K}^{+}$currents in a neuronal cell. Nature 323 . 333-335.

Hille, B. (1984) Ionic Channels of Excitable Membranes, Sinauer, Sunderland, MA.

Hodgkin, A. L., and B. Katz (1949) The effect of sodium ions on the electrical activity of the giant axons of the squid. J. Physiol. (Lond.) 108: 37-77.

Jmari, K., C Mironneau, and J. Mironneau (1987) Selectivity of calcium channels in rat uterine smooth muscle: Interactions between sodium, calcium and barium ions. J. Physiol. (Lond.) 384: 247-26I .

Kaczmarek, L. K. (1987) The role of protein kinase C in the regulation of ion channels and neurotransmitter release. Trends Neurosci. 10 . 30-34.

Keele, C. A., and D. Armstrong (1964) Substances Producing Pain and Itch, Fdward Arnold, London.

Keynes, R. D., and J. M. Ritchie (1965) The movement of labelled ions in mammalian non-myelinated nerve fibres. J. Physiol. (Lond.) 179: 333-367.

Keynes, R. D., and R. C. Swan (1959) The effect of external sodium concentration on the sodium fluxes in frog skeletal muscle. J. Physiol. (Lond.) 147: 591-625.

Konnerth, A., H. D. Lux, and M. Morad (1987) Proton-induced trans- formation of calcium channel in chick dorsal root ganglion cells. $\mathrm{J}$ Physiol. (Lond.) 386: 603-633.

Krishtal, O. A., and V. I. Pidoplichko (1980) A receptor for protons in the nerve cell membranc. Ncuroscience 5: 2325-2327.

Krishtal, O. A., and V. I. Pidoplichko (1981) A receptor for protons in the membrane of sensory neurons may participate in nociception. Neuroscience 6: 2599-2601.

Lee, K., and R. W. Tsien (1984) High selectivity of calcium channels in single dialysed heart cells of the guinea-pig. J. Physiol. (Lond.) 354 : 253-272.

Lindsay, R. M., and H. P. Rang (1987) Effects of bradykinin on the membrane currents of rat sensory neurones in culture. J. Physiol. (in press).

Lindsay, R. M., and H. P. Rang (1988) Activation of protein kinase C causes inward current in a proportion of rat sensory neurones in culture. J. Physiol. (Lond.) 398: 16 p.

Madison, D. V., R. C. Malenka, and R. A. Nicoll (1986) Phorbol esters block a voltage-scnsitive chloride current in hippocampal cells. Nature 321: 695-697.

Malenka, R. C., D. V. Madison, R. Andrade, and R. A. Nicoll (1986) Phorbol esters mimic some cholinergic actions in hippocampal pyramidal neurons. J. Neurosci. 6: 475-480.

Meech, R. W. (1978) Calcium-dependent potassium activation in nervous tissue. Annu. Rev. Biophys. Eng. 7: 1-18.

Miller, R. J. (1986) Protein kinase C: A key regulator of neuronal excitability. Trends Neurosci. 9: 538-541.

Miller, R. J. (1987) Bradykinin highlights the role of phospholipid metabolism in the control of nerve excitability. Trends Neurosci. 10: 226-228.

Moolenar, W. H., and I. Spector (1979a) The calcium action potential and a prolonged calcium-dependent after-hyperpolarization in mouse neuroblastoma cclls. J. Physiol. (Lond.) 292: 297-306.

Moolenar, W. H., and I. Spector (1979b) The calcium current and the activation of a slow potassium conductance in voltage-clamped mouse neuroblastoma cells. J. Physiol. (Lond.) 292: 307-323.

Nestler, E. J., and P. Greengard (1984) Protein Phosphorylation in the Nervous System, Wiley, New York.

Nishizuka, Y. (1984) The role of protein kinase $C$ in cell surface signal transduction and tumor promotion. Nature 308: 693-698.

Nishizuka, Y. (1986) Studies and perspectives of protein kinase C. Nature 312: 315-321.

Nohmi, M., and K. Kuba (1984) (+)-Tubocurarine blocks the $\mathrm{Ca}^{++}$ dependent $\mathrm{K}^{+}$channel of the bullfrog sympathetic ganglion cell. Brain Res. 301: 146-148.

Pennefather, P., B. Lancaster, P. R. Adams, and R. A. Nicoll (1985) Two distinct $\mathrm{Ca}$-dependent $\mathrm{K}$ currents in bullfrog sympathetic ganglion cells. Proc. Natl. Acad. Sci. USA 82: 3040-3044.

Rane, S. G., and K. Dunlap (1986) Kinase C-activator 1,2-oleolylacetylglycerol attenuates voltage-dependent current in sensory neurons. Proc. Natl. Acad. Sci. USA 83: 184-188.

Rang, H. P., and J. M. Ritchie (1968) On the electrogenic sodium pump in mammalian non-myelinated fibres and its activation by various external cations. J. Physiol. (Lond.) 196: 183-221.

Rang H. P., and J. M. Ritchie (1987) Activation of protein kinase C causes a depolarization of the rat vagus nerve associated with increased sodium conductance. J. Physiol. 391: $78 \mathrm{p}$.

Ritchie, J. M., and R. W. Straub (1956) The after-effects of repetitive stimulation on mammalian non-medullated nerve fibres. J. Physiol. (Lond.) 134: 698-711.

Ritchie, J. M., and R. W. Straub (1980) Observations on the mechanism for active extrusion of lithium in mammalian non-myelinated nerve films. J. Physiol. (Lond.) 304: 123-134.

Schwarz, W., and H. Passow (1983) $\mathrm{Ca}^{2+}$-activated $\mathrm{K}^{+}$channels in erythrocytes and excitable membranes. Annu. Rev. Physiol. 45: 359 374.

Shapira, R., S. D. Silberberg, S. Ginsburg, and R. Rahaminotf (1987) Activation of protein kinase $\mathrm{C}$ augments evoked transmitter release. Nature 325: 58-60.

Strong, J. A, A. P. Fox, R. W. Tsien, and L. K. Kaczmarek (1987) Stimulation of protein kinase $C$ recruits covert calcium channels in Aplysia bay cell neurons. Nature 325: 714-717.

Wolff, D. J., and D. W. Sved (1985) The divalent cation dependence of bovine brain calmodulin-dependent phosphatase. J. Biol. Chem. 260: $4195-4202$. 